\title{
ATUAÇÃO DO PROFESSOR MEDIADOR
}

\author{
MEDIATE TEACHER'S ACTIVITIES
}

\section{ACTUACIÓN DEL PROFESOR MEDIADOR}

\author{
Érica Romano Zanquim \\ Grupo de pesquisa GPEI - Educação Infantil: aprendizagem e desenvolvimento profissional \\ em contextos integrados - UNESP/ FCLAr Araraquara. \\ Email: romano.ericac@gmail.com
}

\begin{abstract}
RESUMO
Este artigo apresenta a Educação Infantil como primeira etapa da educação básica, período significativo para a inserção da criança pequena na vida escolar e local no qual ela estabelece desde muito cedo relações de aprendizagens e convívio com outras pessoas. O objetivo deste trabalho é discutir tanto o impacto da prática docente dos professores e de suas concepções acerca da educação infantil quanto as contribuições e implicações desta prática mediadora no desenvolvimento das crianças. Para tanto, nos valemos das prescrições legais e das considerações de teóricos que abordam e fundamentam a prática pedagógica como fazer fundante e estruturante do processo ensino-aprendizagem. Nosso intuito é trazer a reflexão de que como professor, a profissão do pedagogo se constitui em prática social que deve mediar e viabilizar meios para que a criança, em sua primeira etapa de vida, insira-se e participe ativamente no ambiente escolar e se desenvolva integralmente.
\end{abstract}

Palavras-chave: Educação Infantil. Mediação. Professor.

\begin{abstract}
This article presents Early Childhood Education as the first stage of basic education, a significant period for the insertion of the young child in school and local life, in which she establishes early learning relationships and living with other people. The objective of this work is to discuss both the impact of teachers' teaching practice and their conceptions about early childhood education and the contributions and implications of this mediating practice in children's development. To do so, we use the legal prescriptions and the considerations of theorists that approach and base the pedagogical practice as a founding and structuring of the teaching-learning process. Our intention is to bring the reflection that as a teacher, the profession of the pedagogue is a social practice that must mediate and enable means for the child, in his first stage of life, to enter and actively participate in the school environment and develop fully.
\end{abstract}

Keywords: Early Childhood Education. Mediation. Teacher.

\section{RESUMEN}

Este artículo presenta la Educación Infantil como primera etapa de la educación básica, período significativo para la inserción del niño pequeño en la vida escolar y local en el que ella establece desde muy temprano relaciones de aprendizajes y convivencia con otras 
personas. El objetivo de este trabajo es discutir tanto el impacto de la práctica docente de los profesores y de sus concepciones acerca de la educación infantil como las contribuciones e implicaciones de esta práctica mediadora en el desarrollo de los niños. Para ello, nos valemos de las prescripciones legales y de las consideraciones de teóricos que abordan y fundamentan la práctica pedagógica como hacer fundante y estructurante del proceso enseñanzaaprendizaje. Nuestro propósito es traer la reflexión de que como profesor, la profesión del pedagogo se constituye en práctica social que debe mediar y viabilizar medios para que el niño, en su primera etapa de vida, se inserte y participe activamente en el ambiente escolar y se desarrolle completa.

Palabras clave: Educación infantil. Mediación. Maestro.

\section{INTRODUÇÃO}

Considerando a Educação Infantil a primeira etapa da Educação Básica, na qual a criança é inserida desde muito cedo, sendo indissociavelmente cuidada e educada, é importante observarmos que tal inserção no ambiente escolar permite-lhe o estabelecimento de relações pessoais e de aprendizagem cotidianamente. A convivência com os colegas, professores e com o próprio espaço possibilita que ela amplie conhecimentos e construa relações, por vezes profundas e muito significativas, com seus mediadores. Por essa razão, o professor da área de Educação Infantil deve primar pela valorização do sujeito e pelo papel da interação social no processo de aprendizagem e no desenvolvimento da criança, compreendendo-a como um ser social que aprimora suas capacidades afetivas, emocionais, motoras, cognitivas e imitativas no contato com as pessoas, sendo capaz de interagir e aprender com elas.

Neste sentido, na atual legislação educacional, e mais especificamente no Parecer 020/2009, que trata da revisão das Diretrizes Curriculares Nacionais para a Educação Infantil (doravante DCNEIs), a criança é descrita como um ser histórico e de direitos. Significa dizer que ela:

[...] é sujeito histórico e de direitos que se desenvolve nas interações, relações e práticas cotidianas a ela disponibilizadas e por ela estabelecidas com adulto e crianças de diferentes idades nos grupos e contextos culturais nos quais se insere. Nessas condições ela faz amizades, brinca com água ou terra, faz-de-conta, deseja, aprende, conversa, experimenta, questiona, constrói sentidos sobre o mundo e suas identidades pessoal e coletiva, produzindo cultura (BRASIL, 2009, p.7).

Do mesmo modo, na Resolução 05/2009, na qual são fixadas as atuais DCNEIs, a criança é considerada: 
Sujeito histórico e de direitos que, nas interações, relações e práticas cotidianas que vivencia, constrói sua identidade pessoal e coletiva, brinca, imagina, fantasia, deseja, aprende, observa, experimenta, narra, questiona e constrói sentimentos sobre a natureza e a sociedade, produzindo cultura (BRASIL, 2009, p. 14).

Assim, pensando nas necessidades essenciais e específicas destes sujeitos em processo de formação, a Educação Infantil, etapa educacional destinada e organizada exclusivamente para crianças de zero a cinco anos de idade, deve primar por oferecer e ser espaço adequado e privilegiado para a iniciação de importantes relações interpessoais e saberes formais, de forma que a criança conquiste o direito de ser educada não só na esfera privada da família, mas também na esfera pública "[...] por profissionais diplomados distintos dos parentes, para a construção da sua cidadania; e de conviver com a diversidade cultural brasileira, produzindo as culturas infantis, entre elas e entre elas com os adultos" (FARIA, 2005, P.1015). A Educação Infantil coloca-se, portanto, como uma etapa importante de inserção e participação ativa da criança na construção das aprendizagens e interrelações com os educadores que terão por função mediar processos de conhecimento.

\section{O PAPEL DA MEDIAÇÃO NA PRÁTICA DOCENTE}

A educação de crianças demanda um contexto de atendimento às suas especificidades bem como a indissociabilidade entre o cuidar e o educar,

[...] constituindo espaços e tempos, procedimentos e instrumentos, atividades e jogos, experiências, vivências... em que o cuidar possa oferecer condições para que o educar possa acontecer e o educar possa prover condições de cuidado, respeitando a criança em suas inúmeras linguagens e no seu vínculo estreito com a ludicidade (ANGOTTI, 2009, p. 25).

Por essa razão, o professor deve se preocupar em atender, ensinar e entender as crianças em suas formas de significar o mundo e a si mesmas. A atuação profissional passa a ser relevante quando a especificidade de sua tarefa é exercida de forma ética e competente. Isso porque, de acordo com Romano (2015), "o professor é quem atua diretamente com a criança no contexto escolar e seu papel docente não se restringe à transmissão de conteúdos vinculados ao desenvolvimento cognitivo dos alunos, mas, dada sua posição chave, está conectado às dimensões pessoais, motoras e sociais envolvidas no processo educativo". Ainda segundo a autora, a forma de o profissional e a criança se vincularem tem função fundamental nos processos educativos, tendo em vista a interrelação cotidiana desses sujeitos no ambiente 
escolar, cabendo ao professor a importante missão de desenvolver, admitir, cuidar e educar aqueles que lhe são confiados e, sobretudo, promover a evolução deles de modo global na Educação Infantil.

A este respeito, Angotti (2006) reforça o papel significativo do educador, o qual precisa inserir a criança no mundo do conhecimento, na alfabetização de mundo e propiciarlhe desenvolvimento integral, seguro e significativo. Devido ao fato de a atuação do docente estar diretamente relacionada às crianças e às relações humanas, cabe o entendimento de que ele é um referencial para o aluno e meio de comunicação entre eles. Neste contexto, é o professor, em grande medida, quem oferece subsídios para seus educandos constituírem-se. A atuação docente traduz-se, desse modo, em um contexto amplo que engloba diversos elementos tanto do educador quanto do educando. Ao educar e cuidar de crianças pequenas, “o professor não oferece apenas aquilo que sabe, mas também aquilo que é através das interações" (GATTI, 2009, p.37).

Desse modo, evidenciamos a posição de referência do professor para os alunos, pois tomando consciência desse importante papel que desempenha em relação ao outro é que o professor terá condições de se comprometer com a educação e transformação do seu aluno como a de si mesmo. Segundo Romano (2015), a construção de valores por parte do professor é algo muito importante. Isso porque é a partir deles que as práticas docentes são desenhadas e, nesse sentido, os valores que educadores e mediadores trazem para sua prática refletem formam, estimulam, cuidam e interagem com as crianças. Em vista disso, espera-se que o cuidado e o ato educativo possibilitem significativas situações de aprendizagem, desafios e interações adequadas as crianças pequenas, sendo a etapa da Educação Infantil o ambiente para o desenvolvimento das mais diversas linguagens como recurso essencial para que essa criança possa criar, imaginar, sentir, experimentar, se expressar, estimulando seu desenvolvimento integral e indissociavelmente cuidando e educando sob um caráter educativo. Por este motivo, esta etapa, considerada nível de ensino em que se inicia a relação da criança com o saber formal, é espaço privilegiado para o desenvolvimento infantil na sua totalidade.

Tendo em vista os aspectos a serem desenvolvidos na vida das crianças bem como as particularidades da faixa etária compreendida entre zero e cinco anos, as Diretrizes Curriculares Nacionais (doravante DCNEIs) são um importante instrumento para a Educação Infantil (2009), um vez que seu objetivo é orientar e atender as práticas pedagógicas para o atendimento da Educação Infantil. Com o intuito de aplicar o preceito do atendimento integral 
da criança de 0 a 5 anos de idade, as DCNEIs, em seu art. 3, estabelecem um currículo que busca contemplar práticas que articulem as experiências e saberes dos alunos com os conhecimentos que fazem parte do patrimônio cultural, artístico, ambiental, científico e tecnológico, de modo a promover o desenvolvimento infantil. Conforme o art. 4 das mesmas DCNEIs, a criança deve ser considerada o centro do planejamento curricular, um sujeito histórico e de direitos, que nas interações, relações e práticas cotidianas vivenciadas constrói sua identidade pessoal e coletiva, brinca, imagina, fantasia, deseja, aprende, observa, experimenta, narra, questiona e produz sentidos sobre a natureza e a sociedade, gerando cultura, e, para tanto, precisa ser ouvida e entendida na sua forma de significar o mundo e a si mesma.

As formas de olhar a criança e a concepção que se tem sobre sua educação trazem implicações diretas ao papel do educador infantil. Nesse sentido, a formação deste profissional é um aspecto imprescindível para que possa atuar de forma satisfatória, definindo uma profissionalidade que atenda o ser criança, provendo e promovendo seu desenvolvimento integral. $\mathrm{O}$ professor deve exercer seu papel mediador e permanecer atento a cada criança, pensando em suas ações e reações, "sentindo", percebendo seus diferentes jeitos de ser e aprender, de modo a favorecer ao máximo o desenvolvimento do discente. Deve se ater a viver a espontaneidade de cada momento, estabelecer o múltiplo diálogo com os pequenos, detendo a sensibilidade e o conhecimento necessários para fazer provocações diferentes a cada minuto e direcionadas particularmente a cada um de seus alunos, criando, assim, formas de apoio pedagógico.

Hoffmann (2012) versa sobre o que as crianças "precisam" e o que "querem" aprender. A autora não se opõe à existência de um currículo na Educação Infantil, com objetivos a serem seguidos e propostas pedagógicas planejadas pelos professores tendo em vista as necessidades específicas da faixa etária de seus alunos. A ação educativa, segundo ela, não se efetiva pela improvisação e é essencial a intencionalidade educativa do professor, agindo, analisando e replanejando os próximos passos. Porém, Hoffmann (2012) ressalta o perigo da unilateralidade, ou seja, quando apenas o professor propõe ou decide. As propostas pedagógicas devem e precisam ser organizadas pelos professores, mas como também aponta Junqueira Filho (2011), levando em conta os dois lados do planejamento: o que as crianças "precisam" aprender (objetivos do professor) e o que elas "querem" aprender (interesses e necessidades reveladas pelas crianças). 
Quem e o que está diante dos olhos do professor? Justamente e imprescindivelmente, as crianças, interlocutoras diretas do professor e um de seus pares educativos, sem as quais o professor não tem como e nem com quem dialogar; sem as quais o professor não tem condição de avaliar suas crenças e escolhas que produziram sua proposta pedagógica até aquele momento (JUNQUEIRA FILHO, 2011,p. 25).

O tempo e o espaço pedagógico, segundo o referido autor, devem estar atrelados ao possível e ao necessário de cada grupo de crianças: "a criação é compartilhada, em parceria; temos dois criadores em processo - as crianças e seu professor -, portanto, possibilidades de variação contínua" (JUNQUEIRA FILHO, p.73). O que deve se priorizar no planejamento, de acordo com o pedagogo, é justamente o que é mais relevante para elas a cada momento, isto é, propostas que visem a valorizar as experiências de vida de cada criança, suas vivências culturais, raciais, religiosas, etc., suas linguagens expressivas e várias áreas do conhecimento como elementos constitutivos no currículo. Desse modo, o planejamento do professor é muito importante. Torná-lo flexível não significa que não se definam objetivos ou roteiros. É preciso fazer um balanço permanente entre os objetivos delineados e os rumos tomados pelo grupo de estudantes, mesclando aulas expositivas, discussões, tarefas coletivas, tarefas individuais. Da mesma forma, a seleção de conteúdos proposta pela escola precisa ser lida criticamente, analisada em sua essencialidade.

O processo de aprendizagem nunca chega ao fim. O aluno está sempre avançando, evoluindo, construindo novas ideias a respeito de tudo o que vivencia no ambiente escolar e fora dele. Cada passo do aluno precisa ser observado em seu sentido próprio: de mobilização, de processo, de formulação de conceitos. Essas condições serão favorecidas pela organização do trabalho pedagógico, pela abordagem utilizada pelo professor mediador e pela clareza acerca das finalidades de cada momento. Uma abordagem mediadora pode perfeitamente se desenvolver na experiência coletiva da sala de aula. O que a diferencia de uma abordagem "tradicional" é o endereçamento das propostas e o acompanhamento das suas decorrências - a clareza de que o aluno aprende na relação com os outros, interativamente, e o faz a seu tempo, de forma única e singular. Acredito que não seja uma tarefa fácil, mas é possível provocar nas crianças o desejo de aprender por meio da necessidade de enfrentamento a questões bem colocadas do educador. É preciso equilibrar desejo e necessidade. Uma questão bem posta e desafiadora pode suscitar diferentes questionamentos nos alunos.

Para promover aprendizagens significativas, deve-se mobilizar e partir de aspectos de interesse dos alunos, bem como considerar seus conhecimentos prévios para que os saberes 
novos estejam relacionados às estruturas cognitivas que o aluno já possui. Gargallo e Cánovas (1998) (apud MINGUET, 1998) consideram mudanças conceituais processos de evolução e aperfeiçoamento que se dão a partir da interação do conhecimento prévio ativado e da nova informação. Ativar conhecimentos prévios, segundo os autores, é um ótimo ponto de partida para a ação educativa, mas esse pressuposto não se limita a um planejamento inicial, pois é uma ação que se estende a um trabalho contínuo de ativação a cada novidade introduzida.

Para Piaget $(1970 ; 1977)$, a aprendizagem no sentido de desenvolvimento pressupõe desequilíbrio, conflito, reflexão e resolução de problemas. De acordo com o autor, cabe aos adultos mediar a aquisição de ferramentas culturais (linguagem e símbolos) das crianças de forma a levá-las a pensar sobre as suas experiências, articulando ideias e construindo compreensões cada vez mais ricas acerca da realidade. O professor mediador oportuniza e favorece processos de reflexão da criança sobre suas ações: oportunidades de pensar sobre a própria experiência, estabelecendo relações entre ideias e ações e percebendo diferentes pontos de vista para reconstruir suas experiências no plano mental, evoluindo, dessa forma, nos planos moral e intelectual.

Fazer é compreender em ação uma dada situação em grau suficiente para atingir os fins propostos, e compreender é conseguir dominar, em pensamento, as mesmas situações até poder rever os problemas por ela levantados, em relação ao por que e ao como das ligações constatadas e, por outro lado, utilizadas na ação (PIAGET, 1978, p.176).

Também em Vygotsky (1988; 1993), o conceito de mediação é essencial em termos de desenvolvimento. Segundo o autor, há uma grande diferença entre o que uma criança pode aprender sozinha ou com a ajuda de outra pessoa mais experiente, mais competente ou que lhe proporcione desafios adequados ao longo de sua evolução. Seus estudos sobre a noção de ZDP (Zona de Desenvolvimento Proximal) ressaltam a importância do papel mediador do professor e sugerem a necessidade de uma observação simultânea sobre o que a criança “já é ou conhece" e sobre tudo o que "pode vir a ser ou conhecer", isto é, sobre o desenvolvimento real (conquistas ou capacidades já construídas e consolidadas) e sobre a área de desenvolvimento proximal (os conhecimentos "ainda" a desenvolver). Importante destacar que, para Vygotsky, as exigências devem vir acompanhadas de apoios adequados para que cada criança possa alcançar êxito em suas experiências. Para ele, tanto o desafio do professor quanto os recursos de apoio são vistos como mediadores do conhecimento da criança, uma 
vez que, ao enfrentar situações cada vez mais complexas e com maior independência, ela ficará mais autônoma em relação àquela etapa do seu conhecimento.

Em termos de mediação, tanto Piaget quanto Vygotsky fundamentam o papel insubstituível do educador no que concerne os processos favorecedores à construção do conhecimento e defendem a importância da interação adulto/criança e criança/criança para o seu pleno desenvolvimento no plano moral e intelectual. Mediação é aproximação, diálogo, acompanhamento do jeito de ser e aprender de cada criança, dando-lhe a mão, com rigor e afeto, para ajudá-la a prosseguir sempre, podendo escolher seus caminhos e sua trajetória de conhecimento. O tempo individual de cada criança, o qual precisa, sobretudo, ser respeitado, é o tempo de aprender e de ser e não o "de aprender determinado conteúdo"; acompanhá-la passo a passo exige conhecê-la como sujeito, protagonista de sua história, produtora do seu conhecimento. Todo o trabalho pedagógico direciona-se para a busca de desenvolvimento e novos conhecimentos. Os rumos, os objetivos de aprendizagem deverão estar claros para o professor, mas não obrigatoriamente para os alunos. Aquilo que deverá estar claro para ambos são as questões a responder, as situações-problemas propostas, de forma a envolvê-los significativamente.

Despertado o desejo de aprender nos alunos, é compromisso do educador torná-los ativos, criando um cenário educativo provido de recursos e conteúdos do saber. Mobilizados, os alunos viverão diversificadas experiências educativas que poderão ser mais ou menos favorecedoras da sua construção de conhecimento conforme as oportunidades que lhes forem oferecidas. A construção do conhecimento é de natureza única e singular, mas ocorre interativamente e pela mediação do outro, pela socialização. É o professor quem cria, em sala de aula, no ambiente escolar, o cenário educativo, provendo condições mais ou menos favoráveis, recursos mais ou menos amplos, tempos mais ou menos limitadores de aprendizagem. A otimização do espaço de aprendizagem é, portanto, de natureza mediadora, pois é compromisso do docente organizar atividades graduais adequadas ao interesse e possibilidades do grupo, bem como prestar ajuda a cada um dos alunos, ajustando suas intervenções aos progressos e obstáculos individuais.

Mediar a experiência educativa significa acompanhar o aluno em ação-reflexão-ação. Acompanha-se o aluno em processos simultâneos: de aprender (buscar novas informações), de aprender a aprender (refletir sobre procedimentos de aprendizagem), de aprender a conviver (interagir com os outros), de aprender a ser (refletir sobre si próprio como aprendiz). Assim, numa perspectiva mediadora, o cenário educativo se constitui a partir dos alunos e de 
modo favorecer o máximo possível sua ação sobre o objeto de conhecimento. Com base nos princípios de provisoriedade e complementaridade, serão as respostas dos alunos que darão pistas ao professor para continuar refletindo, permanentemente, sobre as novas atividades a propor. Toda a intervenção do professor provoca em si mesmo e no aluno diferentes graus de compreensão. O docente reflete sobre o seu entendimento da criança e a esta última se pergunta também sobre o próprio entendimento acerca das instruções do professor. São momentos reflexivos (mediadores) altamente significativos para ambos. O conhecimento construído pelo aluno em sua interação com o mundo não é uma simples cópia deste, uma vez que a realidade aprendida é uma representação da realidade objetiva, a qual ele internaliza, ajustando-a e transformando-a a partir de sua realidade pessoal.

Uma prática mediadora precisa, assim, desenvolver-se em sintonia com o ciclo da aprendizagem que evolui continuamente de propostas mobilizadoras das experiências educativas e são traduzidas em expressões de sentido construídas pelos educandos. Daí a necessidade de se refletir sobre a finalidade de todas as formas de tarefas e trabalhos propostos aos estudantes, porque poderão estar ou não coerentes aos princípios anteriormente delineados.

A observação é o que me possibilita o exercício do aprendizado do olhar. Olhar é como sair de dentro de mim para ver o outro. É partir da hipótese do momento de educação que o outro está para colher dados da realidade, para trazer de volta para dentro de mim e repensar as hipóteses. É uma leitura da realidade para que eu possa me ler (FREIRE, 1989, p. 3).

Fundamentalmente, é necessária no educador a capacidade de ler a si e ao outro:

É procurando compreender as atividades espontâneas das crianças que vou, pouco a pouco, captando os seus interesses, os mais diversos [...] Por isso é que, em última análise, as propostas de trabalho nascem delas e de mim como professora. Não é de estranhar, pois, que as crianças se encontrem nas suas atividades e as percebam como algo delas, ao mesmo tempo em que vão entendendo o meu papel de organizadora, e não de "dona de suas atividades" (FREIRE, 1989, p.21).

Dessa forma, as instituições de Educação Infantil atuais, sendo um lugar onde as crianças passam boa parte do seu tempo, devem se preocupar com sua efetivação como espaço delas (das crianças), e não apenas para elas. As atividades propostas, quase em sua totalidade apenas pelos adultos, muitas vezes fazem com que a criança desenvolva poucas das inúmeras linguagens e potencialidades que possui. Por essa razão, cabe ao educador o papel de mediar suas vivências, atividades e cuidados, promovendo oportunidades para que a 
criança possa se desenvolver e ser ela mesma por meio da brincadeira, dos questionamentos, do afeto, da interação com os pares, com o espaço e todos os estímulos que possam enriquecer o espaço escolar, tornando-o estimulante, acessível, lúdico e educativo.

\section{CONSIDERAÇÕES FINAIS}

Buscamos demonstrar que a prática pedagógica é também social, devendo viabilizar meios para que a criança, em sua primeira etapa tanto de vida quanto escolar, insira-se e participe ativamente de processos de aprendizagem, de modo a desenvolver-se integralmente. Nesse sentido, a formação do profissional torna-se mais relevante à medida que é exigida dele uma atuação pedagógica satisfatória e que atenda todas as especificidades da infância.

Defendo que o fazer pedagógico requer compromisso e desafio, requer um olhar e uma escuta sensível e atenta à criança, requer novas práticas pedagógicas que garantam o desenvolvimento integral em todos seus aspectos, cuidando e educando, privilegiando o brincar (ludicidade), a experimentação e o relacionamento com o mundo por meio das diferentes linguagens. É importante que o professor esteja envolvido em todos os momentos do ambiente escolar, seja estimulando, seja observando, seja questionando, apoiando ou oferecendo materiais que tornem a atividade mais complexa, fazendo com que a criança se instigue e parta em busca do conhecer. Essas e outras características inerentes a um professor mediador contribuem, sobretudo, para o desenvolvimento das crianças.

Segundo o educador pernambucano Paulo Freire, o papel do professor é estabelecer relações dialógicas de ensino e aprendizagem em que professor ao mesmo tempo ensina e aprende. Juntos, professor e estudante aprendem em um encontro democrático e afetivo no qual todos podem se expressar.

As práticas pedagógicas devem atender e promover o desenvolvimento infantil, devem compreender a criança em sua singularidade, devem permitir-lhe apresentar seu olhar e leitura de mundo, estimulando e propiciando o ato criativo, respeitando sentimentos e emoções, valorizando as diferentes formas de expressão infantil. A criança precisa e tem por direito a promoção de seu desenvolvimento integral, potencial. Assim, se afirma no campo das responsabilidades, o necessário compromisso profissional no investimento de um atendimento educacional de qualidade, porém também revela a responsabilidade da família e da comunidade com este processo, reconhecendo e valorizando a Educação Infantil. 


\section{REFERÊNCIAS}

ANGOTTI, Maristela. (Org.), Educação infantil: da condição de direito à condição de qualidade no atendimento, Campinas: editora Alínea, 2009.

ANGOTTI, Maristela. Educação Infantil: da condição de direito à condição de qualidade no atendimento. Campinas, 2009. (Comunicação oral).

editora Alínea, 2008

(Org.), Educação infantil: Para quê, Para quem e Por quê?. Campinas:

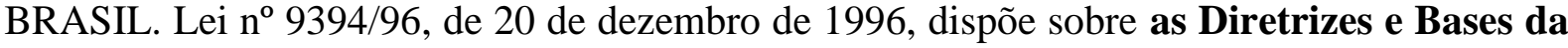
Educação Nacional. Brasília, 1996.

. Diretrizes Curriculares Nacionais para a Educação Infantil, Resolução CNE/CEB N. 20/2009, Brasília/ DF, 2009.

FARIA, Ana Lúcia. Políticas de regulação, pesquisa e pedagogia na Educação Infantil: Primeira etapa da Educação Básica. Educação e Sociedade. Campinas, v. 26, n. 92. p. 10131038, 2005.

FREIRE, Madalena. Primavera Madalena. Porto Alegre: Prefeitura Municipal de Porto Alegre: SME, 1989.

FREIRE, Paulo. Pedagogia dos sonhos impossíveis. São Paulo: UNESP, 2001 (Série Paulo Freire: organização e apresentação Ana Maria Araújo Freire).

GATTI. Bernadete Angelina. Formação de Professores: condições e problemas atuais. Revista Brasileira de Formação de Professores, Cristalina, v.1, n.1, p.90-102, mai. 2009.

HOFFMANN, Jussara. Avaliar para promover: as setas do caminho. 15. ed. Porto Alegre, Mediação, 2014.

HOFFMANN, Jussara. Avaliação mediadora: uma prática em construção da pré-escola à universidade. 33. ed. Porto Alegre: Mediação, 2014c.

HOFFMANN, Jussara. Avaliação mito \& desafio: uma perspectiva construtivista. 44. ed. Porto Alegre: Mediação, 2014d.

HOFFMANN, Jussara. Avaliar: respeitar primeiro, educar depois. 4. ed. Porto Alegre: Mediação, 2013.

HOFFMANN, Jussara. Avaliação e Educação Infantil: um olhar sensível e reflexivo sobre a criança. 20. ed. Porto Alegre: Mediação, 2015.

JUNQUEIRA FILHO, Gabriel de Andrade. Linguagens geradoras: seleção e articulação de conteúdos em Educação Infantil. 5.ed Porto Alegre: Mediação, 2011. 
MINGUET, Pilar Aznar et al. (Org.). A Construção do Conhecimento na Educação. Porto Alegre: Artes Médicas Sul Ltda., 1998. 181 p.

PIAGET, Jean. A construção do real na criança. Rio de Janeiro: Zahar, 1970.

PIAGET, Jean. O julgamento moral na criança. São Paulo: Mestre Jou, 1977.

PIAGET, Jean. Fazer e compreender. São Paulo: Melhoramentos, 1978.

PIAGET, Jean. O nascimento da inteligência. Rio de Janeiro: José Olímpio, 1984.

ROMANO. Erica Carolina. Concepções e Corporeidades Docentes na Educação Infantil. Dissertação de Mestrado em Educação Escolar - Universidade Estadual "Julio de Mesquita Filho" Faculdade de Ciências e Letras (Campus Araraquara). 2015.

VYGOTSKY, Lev Semenovich. A formação social da mente. São Paulo: Martins Fontes, 1988.

VYGOTSKY, Lev Semenovich. Pensamento e linguagem. São Paulo: Martins Fontes, 1988. 